\title{
ATUAÇÃO DO ESTOMATERAPEUTA NO PROCESSO DE REABILITAÇÃO DO OSTOMIZADO.
}

Maria Angela Boccara de Paula

\begin{abstract}
RESUMO: A estomaterapia é uma especialidade da enfermagem, nova e ainda pouco difundida no Brasil. Seu campo de atuação engloba a assistência ao ostomizado, incontinentes, portadores de fístulas e feridas drenantes. A assistência ao ostomizado vem ganhando destaque a nível nacional, sendo de grande importância o envolvimento e participação da equipe multidisciplinar, tendo o enfermeiro estomaterapeuta papel fundamental no processo de reabilitação do ostomizado.Sua atuação se estende da fase pré, trans e pós-operatória mediata e imediata até o acompanhamento ambulatorial sistematizado. O autor discute a atuação do estomaterapeuta em todas as fases da assistência ao ostomizado, relacionando-a com o processo de reabilitação.

UNITERMOS: Ostomia - reabilitação
\end{abstract}

\section{INTRODUÇÃO}

A estomaterapia é uma especialidade da enfermagem ainda nova e gradativamente vem sendo difundida no Brasil. Seu campo de atuação engloba a assistência ao ostomizado, incontinentes,portadores de fístulas e feridas drenantes ${ }^{1.7}$.

A assistência ao ostomizado é uma necessidade que vem assumindo cada vez mais relevância no setor saúde a nível nacional, exigindo a participação e envolvimento de equipe interdisciplinar de saúde, visto que estes pacientes geralmente apresentam alterações biopsicossociais. O estomaterapeuta é elemento integrante desta equipe, tendo papel fundamental na reabilitação do ostomizado. Entende-se por reabilitação o seu retorno à sociedade, em um grau de efetividade, se não igual o mais próximo possível do que possuia antes de sua enfermidade ${ }^{5}$.

Desta forma, o objetivo deste trabalho é abordar a atuação do estomaterapeuta, na assistência ao ostomizado, visando ao processo de reabilitação.

5 Enfermeira Estomaterapeuta.Professor Colaborador Assistente do Departamento de Enfermagem-Universidade de Taubaté. Membro Pleno da Sociedade Brasileira de Estomaterapia e do World Council of Enterostomal Therapists. 


\section{DISCUSSÃO}

A indicação e criação de um estoma traz ao paciente e à familia inúmeras dúvidas, inseguranças e medo do diagnóstico, do ato cirúrgico-anestésico e principalmente da ostomia ${ }^{1,6,8}$. A confecção desta gera temor que, muitas vezes, chega a ser maior do que o da própria doença, uma vez que o tratamento cirúrgico ocorre em momentos de conflito na vida do paciente, nos quais, além deste desconhecimento, a questão vida e morte pode estar presente $^{1.8}$. A atuação do enfermeiro estomaterapeuta deve iniciar-se na fase diagnóstica e pré-operatória, quando paciente e família são abordados em relação ao significado e importância da ostomia, a partir de noções simples e básicas, a fim de familiarizá-los com a questão.

Diversas técnicas e materiais como folhetos explicativos, livros, manequins e materiais específicos para ostomia podem ser utilizados, levando-se em consideração as características individuais de cada paciente.

O planejamento pré-operatório do local do estoma é fundamental para o sucesso da reabilitação. A demarcação pré-operatória do local ideal para a confecção do estoma deve ser realizada até 24 horas antes da cirurgia ${ }^{2,10}$. O estomaterapeuta deve estar ciente das informações médicas, de modo que possa responder a questionamentos do paciente e família, complementar estas informações e reforçar a compreensão dos mesmos sobre a ostomia. O objetivo é a prevenção de problemas, comumente presentes no pós-operatório, como as dermatites periestoma e a dificuldade na adequação e fixação de equipamentos e dispositivos para ostomia ${ }^{9,10}$ e ajudá-lo a se adaptar à nova vida com o estoma, visando à preparação para o autocuidado, fator primordial na reabilitação do ostomizado. Esta atuação deve ser iniciada o mais precocemente possivel, obtendo-se, desta forma, melhor aceitação da cirurgia e da condição física resultante ${ }^{6.10}$.

O planejamento sistematizado da assistência de enfermagem garante ao paciente e à equipe que o assiste diariamente maior segurança, principalmente nos aspectos relacionados à ostomia, uma vez que em nosso país ainda não há profissionais especialistas em número suficiente e nem serviços estruturados com profissionais perfeitamente familiarizados com o cuidado ao ostomizado nas 24 horas do dia.

Este planejamento é extremamente importante e envolve ${ }^{10}$ :

* avaliação e plano de cuidados em relação às necessidades físicas, emocionais, cognitivas, sexuais e de reabilitação;

* demarcação pré-operatória do local ideal do estoma;

* seleção e preparo dos equipamentos e dispositivos específicos para serem utilizados pelo paciente, desde o término do ato operatório;

* seleção dos sistemas de apoio disponíveis na família, instituição e comunidade. 
No periodo pós-operatório, o estomaterapeuta desenvolve as atividades de treinamento para o autocuidado. O paciente é estimulado a aprender as tarefas do cuidado pessoal, da higiene do estoma, da pele periestoma e como utilizar corretamente equipamentos e dispositivos. Neste período, é comum surgirem dúvidas, medos e angústias, que podem manifestar-se ou exacerbar-se. Para muitas pessoas, pode ser uma experiência extremamente dificil adaptar-se às alterações da auto-imagem e à perda do controle esfincteriano, além da sensação de dependência, regressão e rejeição, associados a outros problemas de ordem física como alterações gastrointestinais, urinárias, sexuais e nutricionais, agravadas em alguns casos pela necessidade de tratamentos complementares como a radio e quimioterapia ${ }^{10}$.

A reavaliação dos equipamentos e dispositivos em uso pelo paciente é também importante para o processo de reabilitação; estes devem ser adequados às suas necessidades, ser seguros e oferecer conforto ${ }^{10}$.

O plano de alta hospitalar deve ser sempre elaborado de acordo com as características de cada paciente e deve fornecer informações básicas referentes ao autocuidado. Deve também fornecer principalmente informações sobre os recursos que a comunidade de seu municipio dispõe e orientações sobre os retornos ambulatoriais. Seria muito interessante que as instituições hospitalares pudessem fornecer uma assistência ao ostomizado, garantindoIhe, quando da alta hospitalar, condições de proceder à troca da bolsa coletora sem dificuldades. Infelizmente, ainda nossa realidade é outra. A nossa prática diária no atendimento ambulatorial do ostomizado, do Programa de Ostomizados do SUS-60-Taubaté - São Paulo, tem-nos mostrado que grande parte dos pacientes não recebem orientações pré-operatórias e as orientações pós-operatórias, quando fornecidas, são geralmente superficiais ou limitam-se ao encaminhamento para um serviço ambulatorial. Este Programa é desenvolvido no ambulatório de referência do município de Taubaté, e é cadastrado como pólo de assistência ao ostomizado pela Secretaria de Estado da Saúde de São Paulo, atendendo dez municípios do Vale do Paraíba ${ }^{4}$.

No nivel ambulatorial, o estomaterapeuta muitas vezes inicia a abordagem do paciente e familia em relação ao autocuidado, orientando-os sobre o conceito de estoma, sua indicação, como evitar complicações, visto que a utilização de materiais inadequados, em virtude de uma indicação incorreta, 
gera, além de complicações físicas, ansiedade não só para o paciente e a familia, como também para os profissionais que o assiste.

O acompanhamento e a reavaliação periódica do paciente também possibilitam a deteç̧ão precoce de complicações, permitindo o tratamento destas e, quando necessário, encaminhando-o para os demais integrantes da equipe interdisciplinar.

\title{
CONCLUSÃO
}

O estomaterapeuta é o elemento nuclear da equipe de saúde que assiste o ostomizado, tanto a nivel hospitalar quanto ambulatorial, principalmente por seu domínio nos aspectos relacionados especificamente aos cuidados com o estoma, atualmente ainda pouco difundido entre os profissionais da saúde, tendo em suas mãos a responsabilidade da assistência, de repassar conhecimentos, sensibilizar administradores e profissionais da saúde acerca da necessidade e das vantagens da assistência especializada, além de suas funções administrativas, educativas e investigativas.

\begin{abstract}
The enterostomal therapy is a nurse speciality, yet new and little diffused in Brazil. It comprises the nursing managementwith ostomies, continent diversions, incontinent and acute and chronic wounds. The ostomies management has been very important national wide, and it is necessary the participation and involvementof multiprofessional staff in this assistance.The enterostomal therapist has a fundamental role on the ostomates reabilitation process. His performance begins during the preoperative period and continues up to the ambulatorial accompainment. The author discusses the enterostomal therapist performance in ostomates assistance, regarding to the reabilitation process.
\end{abstract}

KEYWORDS: Ostomy - Reabilitation. 


\section{REFERÊNCIAS BIBLIOGRÁFICAS}

1. CEZARETTI, I.R.; GUIDI, M.E. Assistência de Enfermagem em Estomaterapia: Atividade independente. Acta Paul. de Enferm. v. 1., p. 11-8, 1994.

2. FOULKES, B. Cuidados de enfermaria. In: ORTIZ, H.; RAGUE, J.M.; FOULKES,B. In: Indicaciones y cuidados de los estomas. Barcelona, Jims, 1989, cap.6,p.174-5.

3. PAULA, M.A.B.; PAULA, P.R.; BAYLÃO, M.A.S.; MOREIRA, M.E.; RESENDE, M.H.M.S. Ostomia em portador da sindrome de imunodeficiência adquirida(AIDS). Relato de dois casos. R. Bras. de ColoProctologia, 14(1):32, 1994. Resumo

4. PAULA, M.A.B.; PAULA, P.R. Programa de Assistência ao paciente ostomizado: Relato de experiência. R. Bras. de Colo-Proctologia, 12(1):60, 1992. Resumo

5. RIBEIRO, A.M. O problema da reabilitação: Bases da assistência em equipe. Apresentado ao I Simpósio de profisšionais em estomaterapia, São Paulo, 1991.

6. SANTOS, V.L.C.G. Reabilitação do Ostomizado. Apresentado ao I Simpósio de Profissionais em estomaterapia, São Paulo, 1991.

7. SANTOS, V.L.C.G.; SOUZA JR, A.H.S. Ensino especializado de estomaterapia no Brasil. Helios, 1(3):19, 1993.

8. SOUZA, M.C.; CEREZETTI, C.R.N.; SOUZA JR, A.H.S.; NAHAS,P.; HABRGA-MA, A.; NEDER,M.; PINOTTI, H.W. Mudanças na imagem corporal e alterações psicológicas em pacientes colostomizados e ileostomizados. $R$. Col.Bras.Cir.,13: 159-63, 1986. 
9. SOUZA JR, A.H.S.; BOCHINI, S.; HABR-GAMA, A. lleostomias e colostomias. In: PINOTTI, H.W. Tratado de Clínica Cirúrgica do Aparelho Digestivo. São Paulo, Atheneu, 1994, cap. 144, p.1156-61.

10. ZERBETTO, G.M. Roteiro para avaliação do nível de problemas do paciente ostomizado. São Paulo, 1981, Dissertação(Mestrado). Escola de Enfermagem, Universidade de São Paulo. 